\title{
Re-Conceptualising Racial Identity of Subaltern Malaysian Chinese Community in Tash Aw's We, the Survivors (2019)
}

\author{
Gheeta Chandran \& Foong Soon Seng
}

\begin{abstract}
This paper discusses the dynamics of subaltern identity in Tash Aw's We, the Survivorss (2019) through a guilt-ridden dialogue between an ex-convict and a journalist. Lee Hock Lye often recalls his past life as a working class and "no money Chinese people". The narration reveals double subjugation and accentuates the subaltern Chinese's exclusion in the society. Therefore, the paper aims to analyse the colonial concepts of identity that operates in Malaysia which leads to an imagination of 'Malaysian-Chinese' as 'outsiders' through Lee Hock Lye or more commonly known as Ah Hock's narration as a member of a subaltern Chinese community. Racial identity is constructed, and reconstructed by individuals in the presence of Others, it is implied, imagined and perceived as real. As the subaltern identity of the marginalised people are constantly homogenised and overlooked in the postcolonial studies, it is imperative to re-conceptualise the subaltern Chinese identity in Aw's We, the Survivors (2019) and acknowledge the fact that one's own identity as "fluid and transforming" (Richards, 2010). Colonial constructions of subaltern Chinese identities positioned them as the Other in Malaysia and the homogenisation of subaltern identity further reinforces stereotypes and prejudices. Thus, such homogeneity positions them as the victims of exploitation and discrimination in society. This research aims to explore the notion of identity in a postcolonial literature as contemporary postcolonial setting with its emergence of immigrants, hybrid realms and rise of various cultural diversities, identity often surface as an important issue to analyse. Contemporary identity construction endures colonial constructions of race. It is understood that racial identity is derived from the socio-political context of colonialism and postcolonialism. The research thus will argue the ways in which the construction of identity in the postcolonial world are viewed and presented in a subaltern Malaysian Chinese community as an attempt to understand the dilemma and sufferings of these people through Tash Aw's We, the Survivorss (2019).
\end{abstract}

Keywords: Colonialism, Postcolonialism, Othering, Racial Identity, 'Malaysian-Chinese.'

\section{Introduction}

Born in Taipei and brought up in Malaysia, Tash Aw is the acclaimed writer of The Harmony Silk Factory (2005), Map of the Invisible World (2009), and Five Star Billionaire (2013). Tash Aw's writings mainly highlight the dynamics of national identity; the ways, in which it is negotiated, intervened and produced. He is part of contemporary Malaysian authors who write about their homeland, asserting their sense of belonging to it while living abroad. Aw's 
novels illustrate Malaysia as claimed by Walter Lim (2018), "as the starting point for transnational crossings" (p.9). The pluralistic society in Malaysia is created by coexistence of different races, languages and culture. Hence, these connections enhance the uniqueness of multicultural voice that are ingrained in Tash Aw's writings.

We, the Survivors (2019) is a novel that revolves around Ah Hock, a Chinese subaltern who belongs to a fishing community in Malaysia. The tale begins with his introduction that highlights his simple-minded nature largely influenced by the fact that he was born and brought up in a rural fishing village, Bagan Sungai Yu in Selangor, Malaysia. Ah Hock confesses that he is "trapped in obscurity, hard to get in, hard to get out" (Aw,2019, p.27). His life is a constant failure due to misjudgments and prejudices exerted against him during his various jobs. This further proves the notion social exclusion of the Chinese subaltern community which is marginalised in Malaysia. Therefore the novel elicits a sense collectiveness and reminiscence past as it "connects people across historical as well as national and personal boundaries" (Walder, 2012, p.1). He recalls the events in his life that led him to the prison as a murderer through a series of interviews with a journalist that unravel his experiences that made him an outsider, the Other in his own nation. The interview enables the readers to look into his consciousness and empathise with some of the identity issues such racial ostracism, alienation and great sense of powerlessness about his own fate that are ingrained in his being. Therefore, Ah Hock's voice mirrors the complexity of socio economy and racism experienced by the underprivileged people. Overwhelmed by the oppressions and injustices in his life Ah Hock strives for a sense of belonging and seek to struggle for survival which eventually leads him to violence.

In addition, contemporary postcolonial setting with its emergence of immigrants, hybrid realms and rise of various cultural diversities, identity often surface as an important issue to analyse. Contemporary identity construction endures colonial constructions of race. It is understood that racial identity is derived from the socio-political context of colonialism and postcolonialism. With regards of the notion of Self and the Other, identity often arises as an unresolved issue with several interconnecting discourses (Hall, 2020, p. 200). "The question of the Other became critical and prominent theme" (Pieterse, 1994, p. 130). Pieterse (1994), argues that due to the colonialism and its impact identity becomes a major theme in literature as well as life after World War II, where decolonisation occurred, and imperial identities were decentred. Colonialism and Postcolonialism play a crucial part in making of one's identity and this point is further asserted by Reddy and Glebs (2019):

By researching racial construction in three different multicultural countries, Malaysia, Singapore, and the United Kingdom, we examined how three racial identities, Chinese, Malay, and Indian, are constructed among Malaysians and Singaporeans. We conclude that the socio-political context as understood by the context of colonialism and post-coloniality influenced their racial identity constructions. Participants, regardless of differences in geographical location, used similar colonial constructions of Malay, Chinese, and Indian identities to position themselves as well as Others in their group interaction. (Reddy \& Glebs 2019, p. 792)

Racial discrimination and racial identity among subalterns are common topic of discussion in Malaysian writings however as asserted by Stephen Morton (2010):

Along with other leading contemporary intellectuals such as Edward Said and Homi Bhabha, Spivak has challenged the disciplinary conventions of literary criticism and academic philosophy by focusing on the cultural texts of those people who are often 


\section{Re-Conceptualising Racial Identity of Subaltern Malaysian Chinese Community in Tash Aw's We, the Survivors (2019)}

marginalised by dominant western culture: the new immigrant, the working class, women and the postcolonial subject(Morton,2010, p. 1).

Hence the lack of attention to the subalterns' problems and challenges warrants an emphatical study on the present day disempowered and subjugation subaltern community. With this objective this paper focuses on Tash Aw's We, the Survivors(2019) as the text portrays narratives of subaltern Chinese community's lives in Malaysia. It deals with the question of identity and the role one's race plays in determining one's prospect and future. It also highlights the notion of colonial constructions of subaltern Chinese identities positioned them as the Others in Malaysia and the homogenisation of subaltern identity further reinforces stereotypes and prejudices. Eventually, such homogeneity positions them as the victims of exploitation and discrimination in society. It significant to address this issue as the nonchalant attitude towards this crisis would only further normalise racism associated with the subaltern community.

Therefore, this paper aims to discuss the dynamics of Malaysian Chinese subaltern identity in Tash Aw's We, the Survivors (2019) through an ex-convict, Lee Hock Lye who belonged to working class and "no money Chinese people". The narration reveals double subjugation and accentuates the subaltern Chinese's exclusion in the society. Hence, this study will analyse the colonial concepts of identity that operates in Malaysia which leads to an imagination of 'Malaysian-Chinese' as 'outsiders' through Lee Hock Lye i.e. Ah Hock's narration as a member of a subaltern Chinese community.

\section{The Malaysian Chinese Subaltern}

The history of Malaysia's Chinese subalterns goes back to the colonial period. Malaysia has been inundated with migrant workers since the 1880s. By the end of the nineteenth century and the beginning of the twentieth, it was possible to see Chinese tin mining workers and Indian sugar, coffee and later rubber plantation workers. Many Chinese workers suffering from the aftermath of war, famine and hunger were attracted to the Malay area by the tin mining industry and other agricultural enterprises. In the various industries of tapioca, sugarcane, pepper and gambier farms (Trocki, 2002, p. 299).Due to Western imperial interests and colonial policies that worked to extract wealth and export good consumer goods, large numbers of workers were required. Chinese emigration was born out of external conditions and factors. China's participation in the Opium War and other unequal treaties we concluded with Western colonial powers, such as the British and French (Trocki,2002, p. 298).Chinese emigration, according to Kuhn (2008), was the result of the war triggered by one of these treaties, known as the Nanking Treaty of 1842, which included a provision that China had to agree to open five Chinese ports to British trade in Fuzhou, Amoy, Guangdong, Ningpo and Shanghai, allowing a large number of workers to be recruited, as the Nanking Treaty established a legal basis to permit it (Kuhn, 2008, p. 283). The immigrant workers were poor and in desperate need of jobs, so under a contract, it was very convenient to exploit them. In line with this, Amarjit Kaur (2009) asserts:

The indenture contract, whereby employers used fines to impose wage labour deals, was the key method for hiring Chinese and Indian immigrant labour. The employees were hired for between one and three years to a single employer. The contract was generally a written one, but there were also common verbal agreements. Thus, wage workers were also bound by enforceable labour agreements with their employers, which employers used where available to control their labour costs and supply. Violations of written contracts are deemed to be illegal, not civil offences. At the end of the term, before he was released from his term, the worker had to repay the travel 
and associated expenses (or these were covered by deductions). Since the majority of workers were too poor (they received very low wages), they were re-indentured for another time (Kaur, 2000, p. 7).

Subsequently, as the Malays were replaced by the Chinese workforce, Malaya saw a humongous increase in the mining industry and large-scale tin exports as it was noted that the involvement of the Malay population in paddy-growing and fishing was "more congenial than regimented" and therefore did not match well with the nature of mining that was considered "monotonous work" (Saw \& Cheng, 1971,p. 45).As the influx and need for coolies persisted, a large number of subaltern migrant communities in Malaysia were embodied by Chinese and Indian workers in the 1930s. As Chinese women's immigration to Malaya increased drastically at the beginning of the twentieth century, the sojourning converted to settlement, which gradually changed the demographic profile of the Chinese community in Malaysia (Kaur, 2009, p. 9).

Ah Hock 's grandmother, a young girl of fifteen or sixteen, got on a boat and crossed the seas and landed in Malaysia. Tash Aw's We, the Survivors (2019), is a tale of such a culture. She travelled from Fujian province to Malaya for her safety, afraid of what war could do to a young girl. Because of her relentless anxiety and trauma induced by emigration, her decision was to settle in Bagan Sungai Yu, far from the eyes of the world, in the shadows and secret.It may not be an issue for older generations who are content with "any form of making a living, working the land or the sea" (Aw, 2019, p. 28) to settle in a position with least opportunities in the midst of poverty, but when things have not changed for the younger generation for almost half a century, such as the protagonist Ah Hock, life becomes a war and a relentless dissatisfaction that leads to violence and crime. Various studies on the economic status of the Malaysian fishing community have shown that they live in poverty with a lower than average income. As concluded by Ghani et. al., (2017):

In this report, the majority of fishermen do not have a fixed monthly salary. Their average revenue depends largely on the marine catches they earn when they go out to sea. Some of the fishermen's wives were found to work part-time to earn additional money to supplement the source of income of their family, particularly those from the West Coast of Peninsular Malaysia. (Ghani et. al, p. 342)

Therefore, a brutally unsettling tale of social inequality and prejudice in Malaysia is illustrated in the novel. The tale of Ah Hock depicts a bleak image of life in Malaysia, among the poor community of the country, drawn into a conflict due to his subaltern identity. His inescapable fate opens our eyes to some crucial issues that pervade the social environment of the country, such as racism, sense of alienation, Othering and so on.

\section{Perpetuation of Colonial Racial Identity that Accentuates the Sense of Othering}

Present day racial order in Malaysia, in the feeling of impervious gathering limits, were a side effect of British colonialism of the late 19thand mid 20th century. Preceding 1850, ethnic relations among Asian populaces were set apart by cultural stereotypes and intermittent antagonism, yet there were likewise opportunities for between ethnic coalitions and assimilation. Direct colonial rule brought European racial hypothesis and developed a social and financial request influenced by race.

The ordinary analysis of the race issue in Malaysia (Malaya) is established upon the as far as anyone knows inescapable grindings between ethnic networks with forcefully disparate social customs. In this view, assimilation between the indigenous Malays and the 


\section{Re-Conceptualising Racial Identity of Subaltern Malaysian Chinese Community in Tash Aw's We, the Survivors (2019)}

relatives of workers from China and India was consistently a distant chance. British colonialism made a flimsy segment balance among broadly unique social populaces by an unhindered immigration strategy (Comber, 1983\&Freedman, I960). In addition, the British practice "divide and rule" approaches planted dread and question among the Malays, Chinese and Indian people (Abraham, 1977 \&Cham, 1977). "Divide and Rule" is an arrangement employed by the colonialists to control locals and smother their uprising. As portrayed in the selection over this thought was upheld by the local elites and bourgeois during the colonial time frame and is as yet being sustained in most postcolonial nations today.

When European forces showed up in Southeast Asia in the sixteenth century, the back and forth movement of local realms and broad exchanging networks had just made multiethnic networks. Port urban areas in Sumatra and the Malay landmass contained people groups from all through the Indonesian archipelago, yet in addition from China and India (Lamb, 1964; Reid, 1980; Wheatley, 1980).Throughout the span of the following four centuries, examples of territorial movement quickened, as Western forces disturbed nearby economies yet in addition animated the extension of different zones by setting up new exchanging focuses and expanding the interest in neighbourhood items. Following a few centuries of wavering, the Southeast Asian world was changed in the nineteenth century as the mechanical insurgency in Europe grabbed hold, and as its resonation shook the world.

The interest in crude materials outperformed the limit of customary frameworks to deliver them. Rivalry for control of the flexibly of crude materials (or possible crude materials) animated an explosion of European colonialist development in Southeast Asia. Reacting to the development of world business sectors, capital, work, and new authoritative structures were assembled and sent in an assortment of ways all through Southeast Asia. No place was these functions more terrific than on the Malay promontory. The huge inflows of minimal effort unfamiliar labourers enlisted from China and India brought about the populace portions of these two networks expanding considerably, with Chinese generally working in the tin mines and the Indians taking a shot at the rubber plantation. Movement from somewhere else in the Malay Archipelago was energised as a piece of frontier strategy so as to expand the local food industry, particularly of rice, to take care of the developing populace not occupied with farming.

Since there was turn out accessible for spouses and more established youngsters on the rubber estates, the Indian community now and again included entire families, who were then housed on the estates in the work lines. In any case, their low wages, obligation, helpless economic wellbeing, and physical detachment kept the Indians separated and they would in general exercise little impact on the Malayan culture. Tamils were viewed as more familiar with British principle and more agreeable to teach than the Chinese and to be eager to work for lower compensation than the Malays.

Hence, the book shows that this constant movement creates obstacles for the diasporic and how this leads to the decisions that they take about their lives that eventually affect their children and the next generation. Uncertainty makes them want to stay in the village, though marginalisedthey are emotionally supressed to ever want to move out and forward. Ah Hock asserts:

Imagine that - you come all the way from China, you leave behind war, famine, getting in and out in small boats drifting on the ocean for months, eventually land in some tiny town in Indonesia, find some way of earning a living, working the land or 
the sea. You think you own that tiny bit of scrubby jungle or marsh or wherever you landed, you think you can start a family, start a new life. Then, just when your days and weeks start to feel normal, when your notion of time begins to stretch out into a year, two years, a future - when you look at the place you're in and it no longer feels as if every tree, every blade of grass is out to hurt you, you have to move again. More war, more boats, more swamps (Aw, 2019, p. 28).

In addition, We, the Survivors (2019), seen through Ah Hock's narration emphasises on the fact that he is continually oppressed and pushed to the fringes of the society. He states, "You want me to talk about life, but all I've talked about is failure, as if they're the same thing, or at least so closely entwined that I can't separate the two" (Aw, 2019,p. 3). His inferior personality is imbued in his life and it could be followed through his predecessors' sojourn from China and Indonesia. He proves his feeling of weakness and feebleness for being caught in such an overwhelming life. This is mainly due their Ah Hock complains that:

Our own country must have been changing. And all I could think was: How did we stay the same? The people of the village - my grandparents, my parents, even the children - we must have been trying to protect ourselves against all of the things going on around us. That's what our village meant to us: it existed to prevent us from knowing what was happening in the world (Aw, 2019, p. 29).

The dire situation in the lives of the Chinese subaltern even in the 20th century is primarily caused by the racial segregations that happened during the colonial era. The general public was separated based on racial issues: The world isolated into sections; this world cut in two is possessed by two distinct species. The innovation of the colonial setting is that monetary reality, disparity, and gigantic contrast of lifestyles never come to veil the human real factors. According to Fanon (2007), at the point when you inspect other people the colonial setting, it is apparent that what packages out the world is in the first place the reality of having a place with or not having a place with a given race. In the colonies, the financial foundation is additionally a superstructure. The reason is the result; you are rich since you are white, you are white since you are rich. Similarly, the fate of Chinese subalterns in Malaysia as claimed by the protagonist is determined by the geographical setting there are at, as that decides their profession. As stated in the novel:

My father was a fisherman, just like my grandfather before him. In fact, every man in the village was a fisherman. The country left us no choice - the river coiled around the village, blocking our route south towards the towns, forever nudging us towards the sea. On the other side were the jungle and plantations, which offered prospects even worse than the sea. Back then it was Indians who harvested the palm oil, now it's Bangladeshis and Indonesians - whoever was doing it, we only had to look at their lives to know that their fate was worse than the storms and tides and tangle of nets that we lived with every day (Aw, 2019, p. 22).

Ah Hock shows that the individuals in the town are confined from the remainder of the world. Their lives are essentially stale; with an economy that is exclusively founded on the fishing business along these lines they are helpless before nature's kind heartedness which isn't positive. Whenever when nature strikes, their job would be in danger. Ah Hock's portrayal presents his reality which is a lot of avoided general information that is secured by speculations. He demands that his origin, Bagan Sungai Yu, isn't the Kuala Selangor town. Despite the fact that individuals consider them only one place and accept their lives are a walk in the park loaded up with magnificence and nature's blessing. He attests that his village 


\section{Re-Conceptualising Racial Identity of Subaltern Malaysian Chinese Community in Tash Aw's We, the Survivors (2019)}

is far away, isolated and that is the principle explanation behind numerous strugglesfaced by its kin:

All of us worked at the mercy of the elements - the storms, floods, snakes, worms that burrow into our feet. Nature is beautiful when you look at it from afar, or from a car that passes through it with the windows rolled up. When you have to work outdoors it doesn't seem so beautiful (Aw, 2019, pp. 22-23).

Therefore, the circumstances in his life, the history and the society have created a very visible barrier for the subalterns that position them as the Other in the society. As asserted by Powell \& Menendian (2016), Othering is a concept that not only covers the many manifestations of group identity discrimination, it offers a clarifying context that exposes a collection of common processes and conditions that propagate injustice and marginality centred on the group. Although concrete manifestations of otherness, such as racism or ethnocentrism, are often well understood and thoroughly studied, this wider concept is poorly understood as such. During the 1950s, sociologists created "group position theory" as a method of disclosing race prejudice. According to this hypothesis, group definitions, limits, and implications are the result of complex group and social cycles instead of a consequence of individual connections or inclination (Blumber, 1958). One of the elements of group position theoryis "a feeling that the subordinate group is in some way intrinsically different or alien." This theory may help explain why group-based conflicts involving the overlay of multiple identities may be more intense - the range of ascribed differences between groups is greater" (Smedley, 1998).

Evidently the quotation below highlights how racial prejudice and discrimination has made a subaltern's life as of no consequences and value. Moreover, as mention earlier in this paper the Chinese were projected as the troublemakers during the colonial period for what could be a battle for better wages. The British has created negative images about them as a group indiscipline and rowdies. Thus, this stereotype is perpetuated and sustained even in postcolonial Malaysia. A Chinese youth with money is often assumed as a gangster:

It comes as surprise when two police motorbikes pull up ahead of him - big powerful white police bikes, surprisingly quiet, unlike the noisy scooters that his friends ride. He assumes they've stopped for someone else. Or are just taking a break for an earlyevening drink, but instead they walk swiftly towards him, backing him up against the wall. He doesn't care, he acts tough. Why you stopping me? He says, somewhat aggressively, which only inflames them further. You got warrant? No warrant cannot arrest. Why? Because I'm Chinese is it? They push him against the wall, take off his backpack and find the money, neatly bound by rubber bands in the tight little stacks. When they take them out, they look like small bricks. Chinese kid with load of cash in his bag - no further explanation needed. Samseng. They slap him around the head (Aw 2019, p. 65).

Stereotypes and assumptions are further generated by the assimilation of subaltern identity. Such insularity therefore places them in society as the victims of abuse and discrimination. The subaltern groups are frequently ignored by society and the lack of knowledge of the experiences of subalternity in Malaysia contributes to social marginalisation. In addition, a monolithic perspective on the subaltern groups is provided in the Subaltern Studies by the lack of diversity and subjectivity. Tash Aw's We, the Survivors (2019) articulates the topic of racial discrimination and recounts the struggles of Ah Hock, expressing how those who are 
more fortunate and educated are oppressed at different stages of their lives:

I can only recall that first spring tide in any detail. There was another one the year after, less powerful; and another the following year. Stronger even than the first. The others felt inevitable, as if they were predestined. That first year, the waters subsided a few days later, and we tried to rebuild what we had lost. The second year, we didn't even try. Global warming, people said - strong tide surges would be normal from now on. Apply for a subsidy or loan to buy a new place, someone in the village suggested half-heartedly. But even at that age I knew, like everyone else, that it was hopeless. We were the wrong race, the wrong religion - who was going to give us any help? Not the government, that's for sure. We knew that for no-money Chinese peoples like us, there was no point in even trying. (Aw, 2019, p. 202)

The sense of being the Other prominent in Ah Hock's narration, "That map that you're looking at on your phone, it can't show you the real distance between our side of the river and town on the other" (Aw, 2019, p. 22). Allegorically, Ah Hock is inferring how individuals outside of the town particularly those advantaged neglect to comprehend the truth of the subalterns however only assume, he asserts, "The two places are separated by a sharp curve in the Selangor river, and that small distance - forty, fifty feet in places - sometimes felt like ocean between two continents" (Aw,2019, p. 22).

Ah Hock, find a lot of similarities between him and those Bangladeshi migrant workers working under his friend, Keong due to their race and subaltern position in the society. Due to the victim's status, Ah Hock mentions that it took two months for the police to arrest him because "When the victim is that sort of person, the police don't really care. Yes, that kind of person. A foreigner. An illegal. Someone with dark skin" (Aw, 2019, p. 6). For him, their lives are nothing but daily reminders of the guilt and sense of Othering. These are the sacrifices that had to be made every day, to survive and feed their families. Here, for better prospects, the option was to sit on a boat and move to another world. In Ah Hock, the palpable sense of guilt and isolation leaves a constant desire to escape from everything, from life.

As we walked through the camp the motionless shapes under tarpaulins began to stir and unfurl into human form, men - all men - stretching into life, sitting up, coughing, running their hands across their faces. A few of them looked at us, and though I returned their glances I looked away quickly. Our eyes barely met, but in those two, three seconds, I knew we shared something. A sense of shame. A desire to flee - to escape that camp, that forest, that country, the whole universe that made that life possible (Aw,2019, p. 131).

As he recalls his life in the village where the villagers have bad impressions on Ah Hock as he was raised by a single mother. They once say that "watch out - soon he'll be stealing that bike and riding down to KL with it" (Aw,2019, p. 171). Ah Hock does not like to be treated like "invisible" and he feels alienated in his own country and just like the foreign workers, he feels subjugated and oppressed in the society. He states that "My name will become irrelevant, just as it was before the trial, before the killing, and I will vanish, just like you" (Aw 2019, 131). He believes that the society is treating people from subaltern classes cruelly and they are deemed irrelevant.

Furthermore, Ah Hock is concerned about his being and often questions his sense of Self whether "I was really destined to be me" (Aw, 2019, p. 34). The novel also delves into 


\section{Re-Conceptualising Racial Identity of Subaltern Malaysian Chinese Community in Tash Aw's We, the Survivors (2019)}

Ah Hock's sense of alienation and inferiority as he is treated like an outcast in his own homeland, "that instant we felt like strangers. I didn't want it. One day, it would kill me" (Aw, 2019, p. 24). His inferior status causes him to be marginalised in society. He mentions that "there's always that moment when you feel stuck, one door closes and all the others disappear" (Aw 2019, p. 43). The village creates an invisible barrier for them, and it symbolizes marginality in the novel. Ah Hock describes Keong's background, being "a Chinese boy in the city with no money and no parents to keep him in check - they only do one thing. Join a gang" (Aw, 2019, p. 61). Keong once said that "people like us didn't have time on our side" (Aw,2019, p. 89). To get out of the village and poverty, youngsters like Keong, one of Ah Hock's friends, move to Kuala Lumpur to find work. Keong returns to the village and as Ah Hocknotices, he "belonged to a different world" (Aw, 2019, p. 60) now.

\section{Conclusion}

Racial discrimination can cause distress and disengagement from society and eventually lead to hostility towards society. Individuals that are most likely victims of racial discrimination are highly possible to commit crime and involve in violence (Burt, Simons, \& Gibbons, 2012, pp. 648-677). The research argues the ways in which the construction of identity in the postcolonial world are viewed and presented in a subaltern Malaysian Chinese community as an attempt to understand the dilemma and sufferings of these people through Tash Aw's We, the Survivors(2019) from societal perceptions. As the subaltern identity of the marginalised people are constantly homogenised and overlooked in the postcolonial studies, it is imperative to re-conceptualise the subaltern Chinese identity in Aw's We, the Survivor(2019) and acknowledge the fact that one's own identity as "fluid and transforming" (Richards, 2010). Colonial constructions of subaltern Chinese identities positioned them as the Other in Malaysia and the homogenisation of subaltern identity further reinforces stereotypes and prejudices. Contemporary identity construction endures colonial constructions of race. It is understood that racial identity is derived from the socio-political context of colonialism and postcolonialism. The research thus argues the ways in which the construction of identity in the postcolonial world are viewed and presented in a subaltern Malaysian Chinese community as an attempt to understand the dilemma and sufferings of these people through Tash Aw's We, the Survivors (2019).

\section{References}

Aw, T. (2019). We, the survivors. Penguin.

Blumer, H. (1958). Race prejudice as a sense of group position. The Pacific Sociological Review 1, 1. https://doi.org/10.2307/1388607

Burt, H. C., Simons, R. L., \& Gibbons, F. X. (2012). Racial discrimination, ethnic-racial socialization, and crime. American Sociological Review, 77(4), 648-677. https://doi.org/10.1177/0003122412448648

Cham, B. (1977). Colonialism and communalism in Malaysia. Journal of Contemporary Asia, 7(2), 178-199. https://doi.org/10.1080/00472337785390141

Collin, A. (1977). Race relations in West Malaysia with special reference to modern political economic development [Unpublished doctoral dissertation]. Oxford University.

Comber, L. (1988). 13 May 1969: A historical survey of Sino-Malay relations. Heinemann Asia. 
Fanon, F. (2007). The wretched of the earth. Grove/Atlantic.

Freedman, M. (1960). The growth of the plural society in Malaya. Pacific Affairs, 33, 158168.

Ghani, N. A., Raub, M. A., Adam, F., Abdullah, B., Afgani@Eusoff, Y., \& Ali Puteh, D. A. (2017). Quality of life (QoL) of fishermen in the West Coast states of peninsular Malaysia. International Journal of Academic Research in Business and Social Sciences, 7(4). https://doi.org/10.6007/ijarbss/v7-i4/2808

Hall, S. (2020). Old and new identities, old and new ethnicities. Theories of Race and

Racism, 199-208. https://doi.org/10.4324/9781003060802-16

Harbin, B., Simons, C., Ronald, L., \& Gibbons, X. F. (2012). Racial discrimination, ethnic racial socialization, and crime. American Sociological Review, 77(4), 648 677. https://doi.org/ 10.1177/0003122412448648

Kaur, A. (2009). Labor crossings in Southeast Asia: Linking historical and contemporary labor migration. New Zealand Journal of Asian Studies, 11(1), 276 303. www.nzasia.org.nz/downloads/NZJAS-June09/21_Amarjit_5.pdf

Kuhn, P. A. (2009). Chinese among others: Emigration in modern times. Rowman \& Littlefield.

Lamb, A. (1964). Early history. In Wang Gungwu (ed.). Malaysia: A Survey, 99-112. New York: Praeger.

Lim, W. S. (2018). National and diasporic identity in Shirley Geok-lin Lim's among the white moon faces and Tash Aw's five star billionaire. Asiatic, 12(2), 9-22.

Morton, S. (2010). Marginality: Representations of subalternity, aboriginality and race. $A$ Concise Companion to Postcolonial Literature, 162 - 181. https://doi.org/10.1002/9781444317879.ch8

Pieterse, J. N. (1994). Unpacking the West: how European is Europe? Racism, Modernity, Identity: On The Western Front, 129-149.

Powell, J. A., \&Menendian, S. (2016). The problem of othering. Othering \& Belonging Expanding the Circle of Human Concern, (1), 14-41. https://www.otheringandbelonging.org/wpcontent/uploads/2016/07/OtheringAndBelo nging_Issue 1.pdf

Reddy, G., \&Gleibs, I. H. (2019). The endurance and contestations of colonial constructions of race among Malaysians and Singaporeans. Frontiers in Psychology, 10. https://doi.org/10.3389/fpsyg.2019.00792

Reid, A. (1980). The structure of cities in Southeast Asia, fifteenth to seventeenth centuries. Journal of Southeast Asian Studies , 11, 235-250.

Richards, D. (2010). Framing identities. A Concise Companion to Postcolonial Literature, 9 28. https://doi.org/10.1002/9781444317879.ch1

Saw, S. H., \& Cheng, S. H. (n.d.). Migration policies in Malaya and Singapore. Nanyang Quarterly: Review of Southeast Asian Studies, 1(3), 45-61.

Trocki, C. A. (2002). Opium and the beginnings of Chinese capitalism in Southeast Asia. Journal of Southeast Asian Studies, 33(2), 297-314. https://doi.org/10.1017/s0022463402000152

Walder, D. (2012). Postcolonial Nostalgias: Writing, Representation and Memory (Routledge Research in Postcolonial Literatures) (1st ed.). Routledge.

Wheatley, P. (1980). The golden Khersonese: Studies in the historical geography of the Malay Peninsula before A.D. 1500. University of Malay Press. 


\section{Bio-note}

Foong Soon Seng obtained his $\mathrm{PhD}$ (English Literature) from the University of Malaya. He is currently an Assistant Professor in the Department of Languages and Linguistics, Universiti Tunku Abdul Rahman (Kampar Campus) Perak. His research interests include Feminist Writings (Women's Studies), Colonial \& Post-Colonial Literature, and Malaysian Literature in English.

Email: ssfoong@utar.edu.my

Gheeta Chandran obtained her degree in B.A (Hons) Literature in English (UKM) and M.A Postcolonial Literature in English (UKM). She is currently serving as a lecturer in the Department of Languages and Linguistics, Universiti Tunku Abdul Rahman, Perak. She is interested in Colonial and Postcolonial Literature, Diasporic Issues, Mythologies and Folklores and Malaysian Literature in English based research and projects.

Email: gheetac@utar.edu.my 